http://jmscr.igmpublication.org/home/

ISSN (e)-2347-176x ISSN (p) 2455-0450

crossref DOI: https://dx.doi.org/10.18535/jmscr/v7i7.27

\title{
Gynecomastia in a Quadriplegic Patient Following Traumatic Spinal Cord Injury - Case Report
}

\author{
Authors \\ Sandra Mosses ${ }^{1}$, Unnikrishnan Kartha ${ }^{2}$, Ambili N.R ${ }^{3}$ \\ ${ }^{1}$ Junior Resident, ${ }^{2}$ Professor, ${ }^{3}$ Assistant Professor \\ Department of General Medicine, Govt.T.D Medical College, Alappuzha, Kerala, India \\ *Correspondence Author \\ Sandra Mosses \\ Junior Resident, Department of General Medicine, Govt.T.D Medical College, Alappuzha, \\ Kerala, India-688005
}

\begin{abstract}
Gynecomastia, an excessive development of the mammary glands in men, is a known phenomenon among patients with traumatic spinal cord injury, yet in the last 50 years possible pathophysiology for the same has not been fully elucidated. A clinical examination for the presence of gynecomastia should be performed in every patient with traumatic spinal cord injury and a thorough endocrinological and malignancy workup should follow that. Most of the time, the workup for malignancy turns out to be negative which is reassuring to an anxious patient undergoing a disruption of his body image. Here we present an incidental finding of bilateral gynecomastia in a post traumatic quadriplegic patient admitted in medicine ward.
\end{abstract}

\section{Introduction}

Gynecomastia implies an excessive development of the male mammary gland ${ }^{1}$. A routine physical examination of the breast would disclose a firm or rubbery, mobile, tissue mound arising concentrically from beneath the nipple and areolar region. It is not an uncommon phenomenon among patients with traumatic spinal cord injury. Gynecomastia in the paraplegic / quadriplegic patient population warrants particular attention in the rehabilitation community, because a major aspect of the rehabilitation process concerns reassurance and mental and physical support, which would be required when it appears.

\section{Case Report}

A 50 year old male, with past history of fall from height and compression fracture C5 level 6 months back, quadriplegic and bedridden since then, presented with swelling both breasts for 2 months duration. Patient is on continuous bladder drainage and gives history of multiple episodes of urinary tract infection.

On examination, there was, $6 * 5 \mathrm{~cm}$ non tender, nodular tissue both breasts. Systemic examination: GIT- No hepatosplenomegaly. Examination of external genitalia revealed $\mathrm{B} / \mathrm{L}$ testicular atrophy $(3 * 2.5 \mathrm{~cm})$ with normal pubic and axillary hair.

Nervous system examination- features s/o compressive myelopathy at C5 level. 
Investigations: Routine blood examination, LFT, RFT- Normal. USG breasts and abdomen Normal. Chest $\mathrm{X}$ ray PA view- Normal. In view of $\mathrm{B} / \mathrm{L}$ gynaecomastia, hormone profile was doneFSH: $\quad<0.50 \quad$ (0.9-15); LH: 0.14 (1.5-9.3); Prolactin: 9.48 (2.1-17.7); Testosterone: 21.8 (86.4-788) ; TSH,FT3,FT4-normal

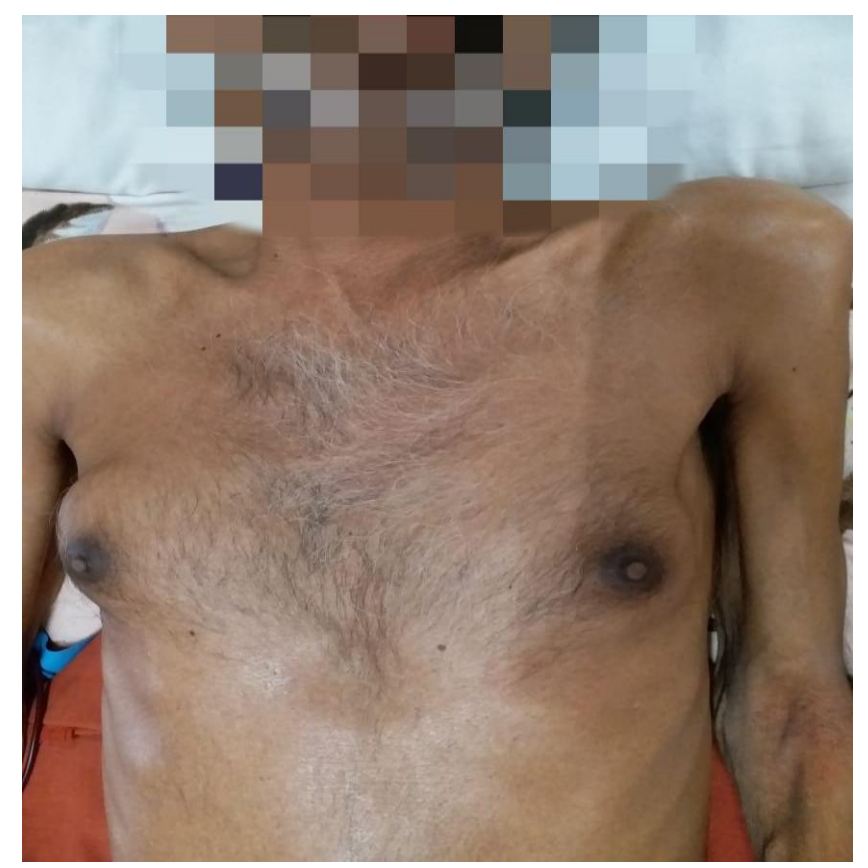

Fig.1 Bilateral Gynaecomastia

\section{Discussion}

Gynaecomastia in adult males rendered paraplegics/tetraplegics by spinal cord trauma has been reported by Cooper and Hoen, ${ }^{2}$ who found an incidence of $22 \%$ in a small series of cases. The occurrence of mammary hypertrophy in paraplegic patients has also been noted by Freeman $^{3}$.

The pathogenesis of this well described entity has not been elucidated clearly. Many theories has been proposed. A transverse myelopathy causes dysfunction in the negative feedback of some of the hypothalamo-hypophyseal-target organ axes. Spinal cord injured humans with lesions above T6 exhibit significantly lower serum LH and testosterone ${ }^{4}$. In most patients with spinal cord injury, a depression of fasting plasma testosterone together with a transient drop in LH and FSH have been noted ${ }^{5}$. It remains unclear whether this abnormality in plasma gonadotropin levels is a direct consequence of a disturbance in the hypothalamic-pituitary-testis axis, a response secondary to primary testicular damage, or a combination of both.

Numerous clinical research studies have resulted in better understanding of the physiological impairments caused by complete or incomplete spinal cord lesions. Specific substances are released from various brain areas and bind to specific receptors in the pituitary gland after physical injury, thus stimulating the synthesis of messenger hormones and their release into the blood stream ${ }^{5}$. These, in turn, bind to receptors in peripheral endocrine glands, stimulating the synthesis of metabolic hormones and their release into the blood stream to affect specialized target tissues. Physical injury of any sort provokes an immediate neuroendocrine response thought to be a part of the physiologic defense mechanism activated after an injury. Neural input arising from the cerebral cortex and the damaged tissues causes increased pituitary secretions of adrenocorticotropic hormone, growth hormone, prolactin and vasopressin, together with a general sympathetic activation ${ }^{6}$. These responses vary considerably in duration, depending on the severity of injury.

Most patients with traumatic spinal cord injury display reduced testosterone levels and can develop testicular atrophy resulting in hypogonadism and infertility. Some have speculated that this may result from recurrent urinary tract infections, impaired vasomotor regulation, increased scrotal temperature, neuropathic bladder and drugs could all be additive factors to the hypothalamic-pituitarytesticular axis dysfunction in the development of hypogonadism and subsequently, gynecomastia ${ }^{4}$. The histological studies of the testes in men with cord lesions, which show atrophy of germ cells but normal or sometimes hyperplastic Leydig cells. Hyperprolactinemia found in some spinal corf injured patients might contribute to testicular hypofunction and hence to the development of gynecomastia ${ }^{7}$. 
The workup requires a careful history-taking, emphasizing the use of drugs, and a physical examination that includes an examination of the testes examined within a month and again after 6 months ${ }^{8}$. Blood chemistry evaluation of liver, renal, and thyroid function is sufficient to cover most conditions associated with gynecomastia. Further endocrine evaluation should include a hormonal profile of serum prolactin, LH, FSH, testosterone. Mammography and ultrasonography are used to differentiate fatty tissue from male breast lesions and soft tissue structures. Mammography or FNA may be very helpful in discriminating between gynecomastia and cancer, although a surgical biopsy should be performed if these procedures do not clearly indicate a benign process.

Most patients with gynecomastia require no therapy other than the removal of any identified inciting cause ${ }^{8}$. The two specific treatment options available, indicated only in rare cases, are medical therapy with antiestrogens or surgical removal ${ }^{9}$.

In our patient, gynecomastia being bilateral, possibility of malignancy can be ruled out. But endocrinological and malignancy work up was done to reassure the patient. Endocrinological workup showed decreased levels of FSH, LH, testosterone and malignancy workup turned out to be negative.

\section{Conclusions}

Spinal cord injury imposes a severe disruption of body image that further deteriorates when gynecomastia ensues. The patient is usually very anxious regarding the appearance of gynecomastia and needs reassurance. Even though in most situations it is unlikely to be malignancy, patient can be reassured after a workup being performed and the possibility of malignancy has been ruled out. Further investigation of the hormonal and the biochemical changes observed in spinal cord injury is needed in order to detect the sequence of these changes and to better understand the underlying mechanism.

\section{References}

1. Heruti RJ, Dankner R, Berezin M, Zeilig G Ohry A. Gynecomastia following spinal cord disorder. Arch Phys Med Rehabil 1997;78:534-7.

2. Cooper IS, MacCarty CS, Rynearson EH. Gynecomastia in paraplegic males. $\mathrm{J}$ Neurosurg. 1950 Jul;7(4):364-7.

3. Freeman L.W. The metabolism of calcium in patients with spinal cord injuries.Ann Surg, 1949, 129:177-184.

4. Naftchi N. Alterations of neuroendocrine functions in spinal cord injury.Peptides vol6,1985, 85-94.

5. Claus-Walker J, Halstead LS. Metabolic and endocrine changes in spinal cord injury: The nervous system before and after transaction of the spinal cord. Arch Phys Med Rehabil 1981;62:595-601.

6. Herman JP, McKlveen JM, Ghosal S, et al. Regulation of the HypothalamicPituitary-Adrenocortical Stress Response. Compr Physiol. 2016;6(2):603-621.

7. Cortes-Gallegos V, Castaneda G, Alonso R. Pituitary-testis relationship in paraplegic men. J Antral 1981;2:326-30.

8. Braunstein, Glenn D. Current Concepts: Gynecomastia. N Engl J Med 1993;328:490-5.

9. Swerdloff RS, Ng JCM. Gynecomastia: Etiology, Diagnosis, and Treatment. 2015,656-657. 